\title{
PROPAGANDA TRANSMIDIÁTICA: UMA ANÁLISE DIALÓGICA DO MECANISMO DE COMUNICAÇÃO EM REDE
}

\author{
TRANSMEDIA PROPAGANDA: A DIALOGICAL ANALYSIS OF THE \\ COMMUNICATION NETWORK MECHANISM
}

\author{
Yan Tavares Bertone ${ }^{1}$ \\ Monique Nascimento Baraúna²
}

Resumo: Este artigo tem como tema a análise dialógica do discurso da campanha transmidiática do gênero propaganda da série televisiva Lincoln Rhyme na esfera da pós-modernidade. A série é derivada do livro "O Colecionador de Ossos", de Jeffery Deaver, traduzido por Ruy Jungmann, lançado em 1997 e adaptado para o cinema em 2000. O problema que motivou a pesquisa é a relação da receptividade e interatividade do sujeito pós-moderno a não se limitar em apenas uma plataforma midiática. Tem-se, com isso, a justificativa da relação do comportamento do sujeito em relação à sociedade de consumo e sua influência na corrente dialógica da Cultura Digital, compreendida por Santaella (2003). Para que a Análise Dialógica do Discurso seja concluída, conceitua-se o conteúdo publicitário como um enunciado capaz de interagir e gerar inferências e enunciados-resposta na arena dialógica de seu meio, com base nas teorias dialógicas compreendidas pelo Círculo de Bakhtin. Como metodologia para a realização deste trabalho, tem-se a pesquisa bibliográfica, de maneira a fundamentar a abordagem do artigo frente às teorias da comunicação e da linguagem. Como resultados da pesquisa desenvolvida, conclui-se que a interação social do sujeito na esfera pós-moderna não se limita a um único modo de expressão e que, com a segmentação das narrativas nas plataformas digitais, é possível obter maior receptividade.

Palavras-chave: Enunciado. Dialogismo. Propaganda. Pós-modernidade. Transmídia.

Abstract: This article has as a theme the dialogical analysis of the discourse of the transmedia propaganda campaign for the Lincoln Rhyme series in the postmodern context. The television series is an adaptation of the book "The Bone Collector", by Jeffery Deaver, release in 1997 and adapted to the cinema in 2000. The research was motivated by the relation between the receptivity and interactivity of the postmodern subject not being limited to just one media platform. In addition to it, there is the justification of the relation of the individual behaviour in relation to the consumer society and its influence in the dialogical current of Digital Culture, comprehended by Santaella (2003). As a process of analysis, the advertising content is conceptualized as an enunciation, capable of interacting and generating interferences and response enunciations in the dialogic arena of its environment, based on the dialogical theories studied by the Circle of Bakhtin. As a methodology of carrying out this work, there is bibliographic research, to support the concepts presented and to base the article's approach in relation to the theories of communication and language. The results of the research show that the social interaction of the individuals in the postmodern context

\footnotetext{
1 Jornalista, mestrando em Linguística Aplicada pela Universidade de Taubaté, E-mail: yanbertone@gmail.com.

2 Jornalista, Mestre em Linguística Aplicada pela Unitau e Coordenadora do Curso de Comunicação Social Rádio e TV da Univap, E-mail: nikebarauna@gmail.com.
} 
does not limits itself in a single mode of expression and that with segmentation of the narratives in different digital platforms, it is possible to obtain a major receptivity.

Key words: Enunciation. Dialogism. Propaganda. Postmodernity. Transmedia.

Data de submissão: 26.04 .2021

Data de aprovação: 21.06.2021

Identificação e disponibilidade:

(https://revista.univap.br/index.php/revistaunivap/article/view/2616, http://dx.doi.org/10.18066/revistaunivap.v27i54.2589).

\section{INTRODUÇÃO}

O presente trabalho se propõe a fazer uma análise do enunciado do gênero propaganda com característica transmidiática na esfera pós-moderna (HALL, 1997), como mecanismo de promoção de uma série televisiva, por meio da criação de um jogo. O objeto é a análise da ação publicitária do lançamento do seriado Lincoln Rhyme pelo canal de televisão por assinatura AXN, com o desenvolvimento do jogo "Lincoln Rhyme Experience".

O problema que motivou a pesquisa é o fato de que, no contexto pós-moderno ${ }^{3}$, uma estratégia direcionada a apenas uma plataforma tende a obter menores atitudes receptivas por parte do público receptor do enunciado propagado, uma vez não ocorre a segmentação do conteúdo para diferentes meios (CITELLI, 2006) e, consequentemente, atrai um único perfil de consumidor. A limitação do conteúdo a apenas uma ferramenta digital segmenta a campanha a apenas o público que tem o letramento necessário para interagir com o que foi criado. Com a ação transmidiática, diferentes narrativas podem ser geradas com segmentações que impulsionam uma única ação final (neste caso, assistir ao seriado).

Pretende-se entender o que possibilita a construção de uma peça transmidiática a partir da necessidade de contextualização da estratégia publicitária - segmentação de conteúdo - paralela ao fenômeno de convergência das mídias (JENKINS, 2006) que permite a criação de peças publicitárias diversas conforme o meio em que se dá sua enunciação.

Como objetivo geral, procura-se investigar como a publicidade transmídia funciona para obter maior engajamento por parte do público. Quanto aos objetivos específicos, têm-se: a) conceituar a estratégia transmidiática como um enunciado no contexto pós-moderno, de acordo com as teorias dialógicas desenvolvidas pelo Círculo de Bakhtin e b) discorrer sobre as finalidades enunciativas no processo sociointeracionista entre enunciador e receptor de acordo com a Análise Dialógica do Discurso.

Como resultados da pesquisa, tem-se a compreensão de que o enunciado propagado na esfera social da pós-modernidade não se limita apenas a um único

\footnotetext{
${ }^{3}$ Entende-se por conceito de pós-modernidade a fundamentação de uma sociedade em constante transformação e descentramento, de interatividade contínua e ininterrupta entre seus indivíduos, por meio do uso de tecnologias. Nesse sentido, Hall (1997) discorre sobre o descentramento e fragmentação da identidade do sujeito, devido a fenômenos como o da globalização e convergência midiática.
} 
espaço (virtual ou não), uma vez que suas características multimodais (KALANTZIS et al., 2016) possibilitam a interação com os sujeitos de diferentes plataformas e, então, maior interatividade com um público em uma campanha publicitária.

\section{METODOLOGIA}

A metodologia utilizada neste trabalho é a de pesquisa bibliográfica, de maneira a compreender a enunciação e constituição dos processos de sentido de um enunciado na esfera da pós-modernidade. A respeito do conceito de pesquisa bibliográfica, tem-se a fala de Lakatos e Marconi (1991), que dizem abranger "toda a bibliografia já tornada pública em relação ao tema de estudo, desde publicações avulsas, boletins, jornais, revistas, livros, pesquisas, monografias, teses, material cartográfico etc". (LAKATOS; MARCONI, 1991).

A linha de pensamento adotada pelos autores para a abordagem da propaganda transmidiática como um enunciado segue a Análise Dialógica do Discurso. Para Cunha (2014), a "Análise Dialógica do Discurso nasce da concepção da Metalinguística, aborda o estudo dos aspectos da vida do discurso que ultrapassam os limites da linguística". (CUNHA, 2014, p.02). Essa abordagem é fundamentada nos estudos desenvolvidos por Bakhtin (1997) e Volochínov (2013), que expandem a compreensão do texto ao caráter de instrumento de comunicação entre sujeitos.

Após a conceitualização a respeito dos aspectos da linguagem e sua relação com as teorias comunicativas, tem-se a compreensão de Hall (1997) e Santaella (2003), como fundamentação da esfera da pós-modernidade e as especificidades dos enunciados propagados nesse meio, constituindo uma arena comunicativa da cultura das mídias e cultura digital (SANTAELLA, 2003).

A Análise Dialógica do Discurso, empregada neste artigo, por mais que não tenha como enfoque os elementos do jogo abordado na propaganda transmidiática (Lincoln Rhyme Experience), faz-se importante para a conceitualização como enunciado característico da pós-modernidade e, para tal, utiliza-se a compreensão de jogo (HUIZINGA, 2000), o letramento lúdico do sujeito como atitude responsiva ao enunciado analisado (SALEN; ZIMMERMAN, 2004; EUTENEUER, 2017) e o fenômeno de convergência das mídias como fomentador de uma ação publicitária transmidiática (JENKINS, 2006).

Por fim, utiliza-se a compreensão de Citelli (2006) sobre o processo de comunicação de um enunciado no contexto multimidiático e relaciona-o à multimodalidade da teoria dos multiletramentos, fundamentada por Kalantzis et al. (2016), como estrutura de compreensão da construção de sentido no emprego da Análise Dialógica do Discurso.

\section{DIALOGISMO NA PÓS-MODERNIDADE}

A priori, de maneira a iniciar a discussão acerca da análise de um enunciado em sociedade, seguindo a abordagem dialógica da análise do discurso (BAKHTIN, 1997), deve-se compreender que cada enunciado se relaciona a um momento sóciohistórico. Dessa maneira, o conceito bakhtiniano de cronotopo ${ }^{4}$ é compreendido como

\footnotetext{
${ }^{4}$ Em Bakhtin: outros conceitos-chave, Amorim (2006) discorre sobre o termo "cronotopia" de Bakhtin; para a autora, "Bakhtin toma-o emprestado à matemática e à teoria da relatividade de Einstein para exprimir a indissolubilidade da relação entre o espaço e o tempo, sendo este último definido como a quarta dimensão do primeiro" (AMORIM, 2006, p. 102). Segundo Amorim (2006), o conceito se familiariza com o de "exotopia", relacionado à ação de separar o sujeito autor de uma obra em si, no
} 
uma estratégia de contextualizar um processo enunciativo em determinado tempo e espaço, como método de compreensão da interação dos sujeitos e seus discursos em sociedade.

De acordo com os estudos do Círculo de Bakhtin, todo o processo enunciativo dos indivíduos está relacionado ao uso da língua. A prática de se comunicar, a concretização do processo enunciativo em si se dá por meio do uso da língua para a geração de enunciados, para que os demais integrantes da esfera social possam compreender e, a partir dos signos, gerar significado sobre o que foi propagado. Para Bakhtin:

\begin{abstract}
Todas as esferas da atividade humana, por mais variadas que sejam, estão sempre relacionadas com a utilização da língua. Não é de surpreender que o caráter e os modos dessa utilização sejam tão variados como as próprias esferas da atividade humana, o que não contradiz a unidade nacional de uma língua. A utilização da língua efetua-se em forma de enunciados (orais e escritos), concretos e únicos, que emanam dos integrantes duma ou doutra esfera da atividade humana. (BAKHTIN, 1997, p. 280)
\end{abstract}

A compreensão de linguagem e uso da língua do Círculo de Bakhtin aborda que todo signo é carregado de uma ideologia, um posicionamento. Ou seja, a geração de significado depende não apenas do signo utilizado para constituir o processo enunciativo, mas também da compreensão do sujeito que recebe, de maneira que a interação entre o indivíduo e seu meio é sempre mediada pela linguagem.

Outro teórico da abordagem sócio-histórica da linguagem e membro do Círculo de Bakhtin é Volochínov (2013), que, ao discorrer sobre o processo enunciativo, afirma que "cada enunciação pressupõe, para realizar-se, a existência não só de um falante, mas também de um ouvinte" (VOLOCHÍNOV, 2013, p. 157). Assim, esclarece-se a interpretação do dialogismo bakhtiniano: todo enunciado se dá como uma resposta, sempre atrelado a demais enunciados de uma esfera enunciativa, compreendida em um determinado tempo e espaço (cronotopia), formando uma espécie de elo (enunciado) em uma corrente (conjunto de enunciados propagados). Para Bakhtin:

A compreensão de uma fala viva, de um enunciado vivo é sempre acompanhada de uma atitude responsiva ativa (conquanto o grau dessa atividade seja muito variável); toda compreensão é prenhe de resposta e, de uma forma ou de outra, forçosamente a produz: o ouvinte torna-se o locutor. (BAKHTIN, 1997, p. 290)

A compreensão do sujeito e de que seus enunciados são vinculados a um determinado tempo e espaço torna necessária a contextualização do jogo Lincoln Rhyme Experience como um enunciado propagado em período compreendido como pós-modernidade, em que a hibridização das narrativas e constituição de identidades facilitam a construção de uma peça publicitária de caráter transmidiático. Isto posto, discute-se sobre os conceitos com a finalidade de esclarecer a análise deste trabalho.

O conceito do pós-moderno vincula-se com a ideia de uma sociedade conectada (SANTAELLA, 2003), com a quebra da barreira do espaço-tempo e a criação de uma arena dialógica pautada no imediatismo, de diálogo constante entre os sujeitos a ela pertencentes.

A partir desse entendimento, retoma-se a compreensão de que a identidade do sujeito é socialmente construída, sendo este um agente em sua esfera social. Tem-

momento de análise, como ferramenta de contextualização do enunciado em um meio, tendo uma observação exterior à que é apresentada pelo autor. 
se, então, com a quebra da barreira espaço-temporal para a constituição do processo comunicativo, um espaço ininterrupto de dialogismo. Esse, por sua vez, é impulsionado pelas ferramentas tecnológicas, que baseiam o conceito de globalização.

Infere-se, portanto, que a cultura e identidade dos sujeitos pós-modernos difere-se das dos demais tempos históricos anteriores à contemporaneidade, em que havia maior limitação espaço-temporal para a realização da comunicação interpessoal, devido a um menor desenvolvimento tecnológico facilitador da atividade comunicativa. A respeito da compreensão de cultura, tem-se a fala de Santaella (2003:

Sempre houve um consenso entre antropólogos de que a cultura está relacionada com ações, ideias e artefatos que os indivíduos numa dada tradição aprendem, compartilham e avaliam. Via de regra, as ações ideias e artefatos são englobados sob uma rubrica mais geral denominada comportamento ou costumes. (SANTAELLA, 2003, p. 43)

A categorização da cultura para a autora, relacionada ao comportamento social, conversa diretamente com a compreensão de Hall (1997) de que o consumismo global possibilita as chamadas "identidades partilhadas", como consumidores, clientes e públicos para o consumo dos mesmos bens e serviços, relacionando os públicos a interação com "mesmas mensagens e imagens - entre pessoas que estão bastante distantes uma das outras no espaço e no tempo" (HALL, 1997, p.42).

Nesta linha de pensamento, observa-se que o comportamento da sociedade influencia, também, no seu modo de consumo, pois são concepções intrinsecamente relacionadas, uma vez que o sujeito, com sua identidade social e historicamente construída, é integrante de um determinado meio e, portanto, apresenta similaridades quanto a sua maneira de agir. Além disso, observa-se que, no cenário pós-moderno, a interação dos sujeitos é atrelada a um dialogismo potencializado pela tecnologia e também ininterrupto. Retoma-se a fala de Santaella (2003), que aborda esse contexto na compreensão de cultura midiática. Para a autora:

\footnotetext{
De fato, a cultura midiática propicia a circulação mais fluida e as articulações mais complexas dos níveis, gêneros e formas de cultura, produzindo o cruzamento de suas identidades. Inseparável do crescimento acelerado das tecnologias comunicacionais, a cultura midiática é responsável pela ampliação dos mercados culturais e pela expansão e criação de novos hábitos no consumo de cultura (SANTAELLA, 2003, p. 59)
}

Vê-se, então, que um único espaço, uma única forma de linguagem (instrumento mediador do processo comunicativo e possibilitador do diálogo do sujeito com seu meio, bem como de sua compreensão de mundo por meio de signos) não se enquadra na pós-modernidade como um todo, sendo preciso construir novas formas de atingir um público específico, ou mesmo criar novas estratégias que potencializam o objetivo final de um enunciado.

A compreensão de cultura das mídias e cultura digital de Santaella (2003) se relaciona, também, à cultura de convergência, que Jenkins (2006) discorre ser marcada pelo "fluxo de conteúdos através de múltiplas plataformas de mídia, à cooperação entre múltiplos mercados midiáticos e ao comportamento migratório dos públicos dos meios de comunicação" (JENKINS, 2006, p.30). Ocorre, então, a hibridização de diferentes conteúdos e diversos canais de comunicação, distanciando da cultura de massa, marcada pela disseminação de um conteúdo ao grande público, 
que tinha pouco poder de agenciamento (escolha do que seria consumido frente ao que era ofertado).

A abordagem deste trabalho é analisar uma campanha publicitária na pósmodernidade que é, também, um enunciado propagado em uma esfera a fim de obter uma atitude responsiva ativa daqueles que por ela são atingidos. As finalidades da publicidade são, neste caso, a compra de um produto, ou a ação de assistir ao seriado em questão: Lincoln Rhyme. Todavia, a esfera social para a qual foi propagada motivou a agência produtora da campanha a inovar, criar uma nova linguagem a fim de ter maior alcance em seu público.

No tópico seguinte, discorre-se sobre a estratégia transmidiática na esfera social da pós-modernidade para a promoção da série televisiva Lincoln Rhyme.

\section{JOGO, TRANSMÍDIA E LINGUAGEM}

Após a compreensão do conceito de enunciado e do contexto da pósmodernidade, bem como da sociedade conectada, é possível traçar características típicas do espaço e do tempo em que a enunciação se constitui. Com a finalidade metodológica deste artigo, vinculada à análise dialógica do discurso, compreende-se o jogo Lincoln Rhyme Experience como um enunciado, constituinte de uma ação transmidiática criada pela agência brasileira Santa Clara, em uma parceria com a desenvolvedora de jogos Mito Games.

Antes de adentrar em detalhes sobre o jogo em si, é preciso recorrer à compreensão do conceito de transmídia de Jenkins (2006). Para o autor, o fenômeno transmidiático ocorre quando:

(...) Uma história transmídia desenrola-se através de múltiplas plataformas de
mídia, com cada novo texto contribuindo de maneira distinta e valiosa para o
todo. Na forma ideal de narrativa transmídia, cada meio faz o que faz de
melhor - a fim de que uma história possa ser introduzida num filme, ser
expandida pela televisão, romances e quadrinhos; seu universo possa ser
explorado em games ou experimentado como atração de um parque de
diversões. Cada acesso à franquia deve ser autônomo, para que não seja
necessário ver o filme para gostar do game, e vice-versa. (JENKINS, 2006,
p.141-142)

Retoma-se brevemente a história por trás da narrativa atual do seriado Lincoln Rhyme. A primeira adaptação do livro "O Colecionador de Ossos", de Jeffery Deaver e traduzido por Ruy Jungmann, lançado em 1997, foi para o cinema, em 2000, com a produção de um longa-metragem estrelado por Denzel Washington e Angelina Jolie.

A adaptação de um livro para o cinema já enquadra a mudança de estilo na composição do contar uma história. O primeiro e original faz parte do contexto literário, com uma linguagem verbal escrita, já o segundo é compreendido no cenário cinematográfico, com recursos audiovisuais combinando som, imagens e gestos. Com isso, percebe-se que, desde a primeira adaptação (livro-cinema) a narrativa já não se apresentava no mesmo gênero ${ }^{5}$ do anterior.

\footnotetext{
${ }^{5} \mathrm{O}$ termo gênero é utilizado como sendo o formato literário, audiovisual em que a narrativa se enquadra na constituição do enunciado no instante de transmitir a história para o leitor/ espectador. Essa compreensão assemelha-se ao que Lopes-Rossi (2002) argumenta sobre gêneros discursivos e suas especificidades, enquadrando-se no formato dos meios pelos quais são enunciados e, assim, concretizando a interação entre o enunciador e o receptor. (LOPES-ROSSI, 2002, p. 4).
} 
Em 2020, a história foi novamente adaptada, mas dessa vez para a televisão pela AXN, canal por assinatura pertencente ao grupo Sony Pictures Entertainment, com a criação da série "Lincoln Rhyme" (personagem principal da trama policial). Temse, a partir daí, uma nova mudança de linguagem, por meio de uma nova maneira de transmitir o conteúdo baseado no livro "O Caçador de Ossos". Entretanto, é interessante ressaltar que não foi apenas a criação da série que possibilitou o sujeito consumidor do produto a conhecer o universo da história.

No Brasil, a agência Santa Clara fez uma parceria com a Mito Games e desenvolveu o jogo Lincoln Rhyme Experience, que pode ser acessado por meio de um hotsite ${ }^{6}$ na página oficial do site da $\mathrm{AXN}$ no Brasil. $\mathrm{O}$ jogo contém quatro fases com modelo point-and-click (apontar e clicar) e acompanham Amelia e Lincoln, personagens oficiais da história, na caçada por pistas para capturar um criminoso. $\mathrm{O}$ jogador toma o lugar da personagem Amelia, que tem uma visão 360 graus do ambiente virtual e é controlada por meio de cliques na tela sobre os objetos de cada sala. O jogo combina a linguagem verbal escrita, oral, visual e auditiva.

A combinação de linguagens na composição do jogo Ihe confere o caráter de multimodal. Para Kalantzis et al. (2016), a multimodalidade se refere ao "uso de diferentes modos de geração de significado: escrito, visual, tátil, áudio e oral" (KALANTZIS et al. 2016, p. 88) no processo enunciativo, tendo o enunciado maior abrangência quanto aos signos utilizados para compô-lo.

O conceito de multimodalidade surgiu vinculado ao conceito de multiletramentos, proposto pelo Grupo Nova Londres ${ }^{7}$, em 1996, com a finalidade de abranger os conceitos de letramento e alfabetização. Para o grupo, multiletramentos não é apenas a constituição do enunciado, mas se caracteriza pela abordagem das diferentes linguagens do local frente ao global na contemporaneidade, de maneira a abranger a diversidade da língua. Além disso, relaciona-se também à variação dos contextos de letramento do sujeito na sociedade: enquanto a alfabetização se limita ao processo de decodificação de um enunciado, compreendendo apenas os signos que o constituem, os multiletramentos vão além, com o uso da linguagem no cotidiano do sujeito, para que ele se comunique com diferentes esferas e seja capaz de compreender e integrar as arenas dialógicas suportadas por diferentes plataformas digitais.

A fim de contextualizar a análise dialógica do discurso utilizada no jogo, compreendido como um enunciado transmidiático propagado em uma esfera social com finalidade de gerar enunciados-resposta de seus receptores, atenta-se para a fala de Citelli (2006), acerca das teorias dialógicas e do comportamento do sujeito frente aos demais enunciados. Para o pesquisador:

As teorias dialógicas, da recepção e das mediaçães vem demonstrando que
os destinatários não são receptáculos vazios, vítimas entorpecidas dos
poderes da manipulação. A rigor, os discursos dos meios de comunicação
entram em "tensão com um conjunto de signos e linguagens que circulam nas
mais diversas relaçães sociais e culturais. A interpretação ou compreensão
das mensagens geradas pela televisão, rádio ou jornal fica, nesta óptica,
dependente dos ajustes discursivos mais amplos que os receptores/

\footnotetext{
${ }^{6}$ Site secundário vinculado a um domínio principal, que funciona para a promoção de um produto por tempo indeterminado.

7 O Grupo Nova Londres (New London Group) foi assim denominado após pesquisadores da área da educação e da linguística se reunirem em New London (Nova Londres), nos Estados Unidos, para discutir sobre o uso da linguagem na modernidade. Os pesquisadores foram: Bill Cope, Mary Kalantzis, Gunther Kress, James Paul Gee e Norman Fairclough. (MOURA; ROJO, 2019).
} 
A citação acima se relaciona às teorias dialógicas de que um enunciado é também uma resposta, formando uma corrente enunciativa de demais enunciados. Essa percepção está atrelada à ideia de que os sujeitos receptores de uma mensagem, no processo de interação social, são indivíduos capazes de não apenas agenciar (mesmo que de maneira limitada) o que irão consumir, mas também são responsáveis pela compreensão do enunciado que lhes alcança para conseguirem gerar significado. Assim, um mesmo enunciado pode receber diferentes interpretações.

Parte do layout da plataforma do jogo pode ser visto na imagem abaixo, permitindo ter maior noção dos signos utilizados para compor a peça publicitária:

Figura 1 - Lincoln Rhyme Experience ${ }^{8}$

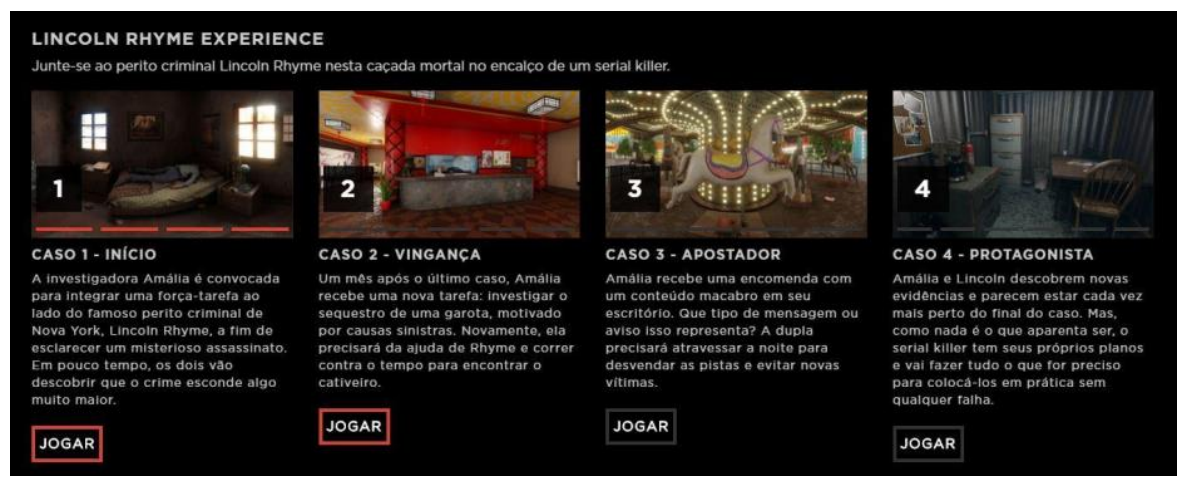

Fonte: AXN Brasil (2020).

Observa-se que a cada novo produto criado para contar a história do livro "O Caçador de Ossos", novas linguagens são utilizadas e que em nenhuma das adaptações tem a necessidade de conhecer as demais para poder consumir o conteúdo disponibilizado pelos enunciadores.

A adaptação do livro para o jogo pode ser compreendida a partir do que Citelli (2006) relata a respeito da migração de signos verbais para as diferentes plataformas midiáticas. Segundo o autor:

Os média, em suas intercorrências sinergéticas, capacidade de fundir linguagens, cruzar signos, permitem a migração verbal por diferentes suportes, compreendendo todos que retroalimentam o rádio, a televisão, o jornal e o próprio público, que, por seu tempo, pode reenviar as estruturas linguísticas aos meios de comunicação ajudando a configurar ou reconfigurar o modo de as mensagens entrarem em circulação social. (CITELLI, 2006, p. 73)

Ressalta-se, aqui, que a segmentação da linguagem utilizada na estratégia transmidiática de criação do jogo Lincoln Rhyme Experience apresenta potencial maior na atitude responsiva daqueles afetados pela ação, uma vez que o conceito de jogo carrega consigo a criação, também, do que Huizinga (2000) chama de "círculo mágico", atrelado ao espaço-tempo. Para o autor:

A arena, a mesa de jogo, o círculo mágico, o templo, o palco, a tela, o campo de tênis, o tribunal etc., têm todos a forma e a função de terrenos de jogo, isto

\footnotetext{
${ }^{8} \mathrm{~A}$ captura de tela presente neste artigo refere-se à estrutura do site na época de acesso: Outubro de
} 2020. 
é, lugares proibidos, isolados, fechados, sagrados, em cujo interior se respeitam determinadas regras. Todos eles são mundos temporários dentro do mundo habitual, dedicados à prática de uma atividade especial. (HUIZINGA, 2000, p.11)

A afirmação acima permite refletir que, pela estratégia publicitária transmidiática tratar-se de um jogo, o comportamento dos sujeitos que com ela irão interagir é, consequentemente, condicionado a atuar dentro dos limites do círculo mágico (HUIZINGA, 2000) do objeto lúdico.

Sobre o conceito de círculo mágico, Huizinga (2000) o elabora segundo a compreensão de que as personagens e jogadores criam um espaço de jogo, físico ou virtual, para atingir os objetivos finais, seguindo as regras necessárias para isso, sendo estas já estabelecidas como a regra do jogo. Ou seja, o sujeito jogador é envolvido pela trama que gira em torno do jogo. Nesse sentido, o jogo não é tido apenas como um objeto com características rígidas, ele é uma esfera de socialização entre os sujeitos jogadores, que representam seus papéis (funções) para que as regras sejam mantidas, mas também são os responsáveis por manter o círculo mágico por eles criado.

O jogo ser compreendido como um enunciado, dentro da concepção da Análise Dialógica do Discurso, lhe dá a capacidade de gerar outros enunciados-resposta, essa sendo atrelada às ações do jogador (tido neste momento como o consumidor ideal do produto, um sujeito que já interage com a plataforma) e que os consumidores se tornem mais propícios a se relacionarem com conteúdos ligados à série.

Essa característica pode potencializar suas atitudes responsivas esperadas pelos autores da ação transmídia (agência Santa Clara e Mito Games) pelo simples fato de o sujeito interagir com o jogo e criar uma afinidade com a trama a partir disso, aumentando as chances de consumir o produto final.

Acerca do comportamento do sujeito no ato de jogar, tem-se também a fala de Salen e Zimmerman (2004), que dizem:

$\mathrm{O}$ ato de jogar não vem apenas do jogo em si, mas da maneira como os jogadores interagem com o jogo para jogá-lo. Em outras palavras, o tabuleiro, as peças e até mesmo as regras do xadrez não podem constituir, por si só, um jogo significativo. $O$ jogo significativo emerge da interação entre os jogadores e o sistema do jogo, bem como do contexto em que o jogo é jogado. Entender essa interação nos ajuda a ver o que está acontecendo quando um jogo é jogado. Uma forma de enquadrar o que os jogadores fazem quando jogam é dizer que estão fazendo escolhas. Eles estão decidindo como mover suas peças, como mover seus corpos, quais cartas jogar, quais opções selecionar, quais estratégias tomar, como interagir com outros jogadores. Eles ainda têm que fazer a escolha de jogar ou não! (SALEN; ZIMMERMAN, 2004, p.46, tradução nossa)

O posicionamento dos autores permite compreender que o contexto do jogo e o comportamento dos sujeitos no ato de jogar influencia suas ações na interação com o objeto lúdico. Paralelo a isso, Euteneuer (2017) discorre acerca do letramento de jogo para que seja possível a integração do jogador com os componentes do enunciado lúdico. Fundamenta-se essa questão de modo a esclarecer que, ao categorizar o jogo como um enunciado propagado como uma peça publicitária a fim de atrair clientes para o conteúdo abordado, toma-se como base a máxima de que os sujeitos receptores terão letramento para interagir com os diferentes signos que compõem o produto. Euteneuer (2017) relata:

Os teóricos tentaram definir o termo letramento lúdico em uma variedade de 
contextos de jogos: mais notáveis são o uso de" letramento lúdico "de James J. Bono e Ben McCorkle para discutir como os jogadores falam sobre jogos e o termo" letramento ludo"de Zagal, usado para explicar como a aprendizagem ocorre em jogos digitais. No entanto, o que é necessário não é um entendimento mais profundo da linguagem dos jogos - uma alfabetização em jogos, conforme apresentado por Zimmerman - mas sim um entendimento mais profundo das maneiras pelas quais o jogo pode ser expressivo e persuasivo. A alfabetização lúdica opera por meio das dimensões corporal, cultural, espacial e temporal; pode iluminar como a brincadeira funciona com nosso mundo e por meio de nossos corpos para criar significado, gerar experiência por meio da performance e cultivar a memória. (EUTENEUER, 2017, tradução nossa)

Mesmo ao se contrapor ao entendimento de letramento lúdico apresentado por Salen e Zimmerman (2004), Euteneuer (2017) não se distancia totalmente do que os autores relatam acerca do contexto de jogo. É possível inferir, por meio da interpretação da citação acima, que o autor enquadra o jogo no conceito de multimodalidade, sendo ele constituído por diferentes signos e, consequentemente, a compreensão do sujeito jogador deve ter a abrangência de não apenas decodificar a mensagem do jogo, mas tornar-se membro de seu contexto para atuar no ato de jogar.

Retoma-se nesse momento a questão da pós-modernidade atrelada à mudança de comportamento do consumidor: tem-se na campanha analisada, a criação de um produto derivado do universo da série e não necessariamente o sujeito atingido pelo enunciado de cunho publicitário responderá de maneira ativa e positiva como é esperado pelos autores da campanha e empresa responsável pela divulgação da série. Contudo, a segmentação no direcionamento da campanha aumenta as chances de atingir o perfil de cliente ideal, conhecido na publicidade como buyer persona $^{9}$, pois a identidade presumida desse sujeito possibilita um enunciado que dialogue com suas especificações e, dessa forma, atinja respostas mais ativas, seja por uma ação ou mesmo por um compartilhamento do conteúdo, gerando um eco na cadeia discursiva.

\section{CONCLUSÃO}

Este trabalho foi desenvolvido com o objetivo de analisar a linguagem utilizada na campanha transmidiática para a promoção da série Lincoln Rhyme e, para uma melhor compreensão do objeto estudado, foi necessária sua contextualização no ambiente pós-moderno, bem como uma pesquisa sobre o modo de consumo e interação dos sujeitos.

O entendimento de linguagem que fundamenta a análise realizada no artigo foi o de dialogismo, abordado por Bakhtin (1997) sobre o enunciado em uma constante relação de resposta em uma corrente sustentada pela interação dos sujeitos, contextualizada em um determinado espaço-tempo, entendida pelo teórico como o conceito de cronotopo (fundamentado para a realização de uma análise acerca do comportamento de um povo em relação ao tempo e espaço). A partir disso, os conceitos de pós-modernidade, cultura e comportamento de consumo dos sujeitos em uma esfera foram fundamentados por Hall (1997), Santaella (2003) e Citelli (2006), para maior compreensão do tipo de sujeito receptor da campanha publicitária em si.

\footnotetext{
9 O buyer persona é o perfil ideal de um cliente para quem a campanha publicitária é destinada. No âmbito da teoria da linguagem, também seguida neste artigo, pode-se relacioná-lo com o sujeito presumido (BAKHTIN), para quem um determinado enunciado é destinado, previamente pensado antes de ser concretizado no processo de enunciação da esfera social em que será propagado. (REZ, 2016).
} 
Além da compreensão de dialogismo e da contextualização enunciativa do objeto tido como corpus de análise do trabalho, fundamentou-se neste artigo a discussão acerca do letramento e compreensão de jogo por meio dos estudos de Huizinga (2000), Salen e Zimmerman (2004) e Euteneuer (2017), de maneira a possibilitar a análise quanto ao comportamento do sujeito receptor do enunciado (o jogador do jogo em si, consumidor do produto apresentado), bem como sua capacidade de resposta, interação com o jogo Lincoln Rhyme Experience e quais habilidades seriam necessárias para a facilitação da atitude responsiva, sendo a última fundamentada a partir do conceito de letramento lúdico e digital quanto à multissemiose.

Conclui-se, pois, que a ação transmidiática, teoricamente fundamentada nesse trabalho pela fala de Jenkins (2006) e de Citelli (2006), foi fundamental para a segmentação de público com a finalidade de obter uma atitude responsiva ativa do receptor do enunciado propagado, uma vez que toda ação enunciativa é mediada pela linguagem e a identidade presumida do sujeito torna-se elemento chave para a construção de um enunciado específico e constituição do processo dialógico na cadeia discursiva.

A fundamentação dos conteúdos multissemióticos em diferentes plataformas, como apresentado por Citelli (2006), esclareceu acerca do comportamento de consumo do sujeito na esfera pós-moderna (HALL, 1997) e da cultura digital (SANTAELLA, 2003), pois serviu como aprofundamento das teorias da comunicação e suas intersecções com as teorias da linguagem, no que se refere à constituição do enunciado no processo dialógico em um contexto específico.

Por fim, também foi possível observar que a criação de um jogo derivado da série televisa apresenta elementos de jogos com potencial para uma interação mais engajada por parte dos consumidores do produto, mesmo que suas respostas ao produto sejam meros compartilhamentos em rede, formando ecos em suas esferas, mas que ainda sim causam maior alcance do enunciado transmidiático.

\section{REFERÊNCIAS}

AMORIM, M. Cronotopo e Exotopia. In: BRAIT, B. (org.) Bakhtin: outros conceitoschave. São Paulo: Contexto, 2006.

AXN BRASIL. Lincoln Rhyme Experience. [S.I]: AXN Latin America, 2020. Disponível em: https://mitogames.com.br//rxp/selecao-de-capitulo/. Acesso em: 1 mar. 2021.

BAKHTIN, M. Estética da Criação Verbal. Tradução de Maria E. G. Pereira. São Paulo: Martins Fontes, 1997.

CITELLI, A. Palavras, meios de comunicação e educação. São Paulo: Cortez, 2006.

CUNHA, R. C. Estudos Dialógicos do Discurso e Práticas de Ensino-Aprendizagem de Língua Portuguesa: A Proposta Direito de Aprender em Sala de Aula. In. CONGRESO INTERNACIONAL ASOCIACIÓN DE LINGÜÍSTICA Y FILOLOGÍA DE AMÉRICA LATINA, 17., 2014, João Pessoa. Anais [...].J oão Pessoa: ALFAL, 2014. Disponivel em: http://www.mundoalfal.org/CDAnaisXVII/trabalhos/R1212-1.pdf. . Acesso em: 1 mar. 2021. 
EUTENEUER, J. Toward a Ludic Literacy: Procedure, Imageword, and Metaphor in Digital Games. 2017. Disponível em: https://www.videogameartgallery.com/vgareader-articles/toward-a-ludic-literacy-procedure-imageword-and-metaphor-in-digitalgames. Acesso em: 1 mar. 2021.

HALL, S. A identidade cultural na pós-modernidade. Rio de Janeiro: Lamparina, 1997.

HUIZINGA, Johan. Homo Ludens. São Paulo: Perspectiva, 2000.

JENKINS, H. Cultura da Convergência. São Paulo: Aleph, 2006.

KALANTZIS, M. et al. Literacies. Sidney: Cambridge University Press, 2016.

LAKATOS, E. M.; MARCONI, Marina de A. Fundamentos da Metodologia

Científica. 3.ed. São Paulo: Atlas, 1991.

LOPES-ROSSI, M. A. G. O desenvolvimento de habilidades de leitura e de produção de textos a partir de gêneros discursivos. In: LOPES-ROSSI, Maria A. G. (Org.).

Gêneros discursivos no ensino de leitura e produção de textos. Taubaté: Cabral, 2002. p. 19-40.

MOURA, E.; ROJO, R. Letramentos, mídias, linguagens. São Paulo: Parábola, 2019.

REZ, R. Marketing de Conteúdo: a moeda do século XXI. São Paulo: DVS Editora, 2016.

SALEN, K.; ZIMMERMAN, E. Rules of Play: Game Design Fundamentals.

Cambridge: MIT Press, 2004.

SANTAELLA, L. Culturas e artes do pós-humano: da cultura das mídias à cibercultura. São Paulo: Paulus, 2003.

VOLOCHÍNOV, V. A construção da Enunciação e Outros ensaios. São Carlos: Pedro \& João Editores, 2013. 